\title{
Emergency medicine training in Canada: a survey of medical students' knowledge, attitudes, and preferences
}

\author{
Morgan Hillier, MD, BSc*; Shelley McLeod, MSc, BSc (Hons) ${ }^{\dagger}$; Danny Mendelsohn, MD*; \\ Bradley Moffat, MD*; Audra Smallfield, MD*; Akram Arab, MD*; Ashley Brown, MD*; \\ Robert Sedran, MD, MSc, BESc* ${ }^{\dagger}$
}

\section{ABSTRACT}

Objectives: The objective of this study was to assess medical students' knowledge of and attitudes toward the two Canadian emergency medicine (EM) residency programs (Fellow of the Royal College of Physicians of Canada [FRCPC] and Certificant of the College of Family Physicians-Emergency Medicine [CCFP-EM]). Additionally, medical students interested in EM were asked to select factors affecting their preferred choice of residency training program and their intended future practice. Methods: Medical students enrolled at The University of Western Ontario for the 2008-2009 academic year were invited to complete an online 47-item questionnaire pertaining to their knowledge, opinions, and attitudes toward EM residency training.

Results: Of the 563 students invited to participate, 406 $(72.1 \%)$ completed the survey. Of the respondents, 178 (43.8\%) expressed an interest in applying to an EM residency training program, with $85(47.8 \%)$ most interested in applying to the CCFP-EM program.

The majority of respondents (54.1\%) interested in EM believed that there should be two streams to EM certification, whereas $18.0 \%$ disagreed. Family life and control over work schedule appeared to be common priorities seen as benefits of any career in EM. Other high-ranking factors influencing career choice differed between the groups interested in CCFP-EM and FRCPC. The majority of students interested in the CCFP-EM residency program (78\%) reported that they intend to blend their EM with their family medicine practice. Only $2 \%$ of students planned to practice only EM with no family medicine. Conclusions: This is the first survey of Canadian medical students to describe disparities in factors influencing choice of EM residency stream, perceptions of postgraduate work life, and anticipated practice environment.

\section{RÉSUMÉ}

Objectifs: L'objectif de cette étude était d'évaluer les connaissances et les impressions des étudiants en médecine en ce qui concerne les deux programmes canadiens de résidence en médecine d'urgence (MU) (Associé du Collège royal des médecins du Canada [FRCPC] et du Collège des médecins de famille (médecine d'urgence) CCMF [-MU]) En outre, les étudiants en médecine qui s'intéressaient à la MU ont été invités à sélectionner les facteurs influençant leur premier choix de programme de résidence et la pratique future qu'ils prévoient choisir.

Méthodes: Les étudiants en médecine inscrits à l'université de Western Ontario pour l'année scolaire 2008-2009 ont été invités à remplir un questionnaire en ligne comportant 47 questions sur leurs connaissances, leur opinion et leurs impressions à l'égard du programme de résidence en médecine d'urgence.

Résultats: Parmi les 563 étudiants invités à participer, 406 $(72,1 \%)$ ont répondu au sondage. Parmi les répondants, 178 $(43,8 \%)$ ont démontré un intérêt pour la demande d'admission à un programme de résidence en $\mathrm{MU}$, avec 85 répondants $(47,8 \%)$ démontrant le plus d'intérêt à s'inscrire au programme CCMF-MU.

La plupart des répondants $(54,1 \%)$ intéressés par la MU estiment qu'il devrait y avoir deux cheminements menant à la certification en $\mathrm{MU}$, tandis que $18,0 \%$ des répondants étaient en désaccord. La vie de famille et le contrôle des horaires de travail semblaient être des priorités communes et constituer des avantages connus et recherchés dans toute carrière en MU. Une différence a été observée relativement aux autres facteurs ayant une très grande influence sur le choix de carrière entre les groupes intéressés par le CCMFMU et le FRCPC. La plupart des étudiants intéressés par le

From the *Schulich School of Medicine and Dentistry and the †Division of Emergency Medicine, The University of Western Ontario, London, ON.

Correspondence to: Dr. Robert Sedran, Room E1-100 Westminster Tower, 800 Commissioners Road, London, ON N6A 5W9; rsedran@uwo.ca.

Submitted July 23, 2010; Revised January 26, 2011; Accepted February 1, 2011.

This article has been peer reviewed. 
programme de résidence CCMF-MU (78\%) ont déclaré leur intention de jumeler leur MU à leur pratique en médecine familiale. Seulement $2 \%$ des étudiants prévoyaient avoir une pratique en $\mathrm{MU}$ sans médecine familiale.

Conclusions: II s'agit d'un premier sondage effectué auprès des étudiants canadiens en médecine pour décrire les disparités dans les facteurs qui influencent le choix des cheminements de résidence en $\mathrm{MU}$, les perceptions de la vie professionnelle après les études supérieures et l'environnement dans lequel les étudiants prévoient pratiquer.

Keywords: career choice, emergency medicine, medical student, residency
Canada is unique in that it has two separate and distinct emergency medicine (EM) training programs governed by two different colleges. Both the Royal College of Physicians and Surgeons of Canada (RCPSC) and the College of Family Physicians of Canada (CFPC) offer EM residency training programs, outlining goals and objectives for their respective graduates. The RCPSC offers a 5 -year EM residency training program with certification as a Fellow of the Royal College of Physicians of Canada (FRCPC). The CFPC offers a 2-year residency training program in family medicine with the option of an additional year of training in EM to obtain the Canadian College of Family Physicians Emergency Medicine (CCFP-EM) certification.

The FRCPC residency training program aims to produce academically oriented emergentologists who often blend their clinical practice with nonclinical responsibilities such as administrative, research, and teaching roles. Not surprisingly, the majority of FRCPC graduates tend to practice EM in tertiary care

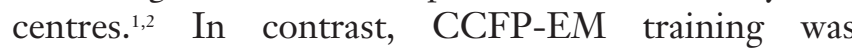
intended to improve emergency medical care delivered by family physicians through "special competency" training, not to produce career emergentologists.

Over the last decade, there has been considerable debate regarding Canada's two EM certification streams. ${ }^{1-10}$ It has been argued that the Royal College and CCFP-EM training streams produce physicians with different skill sets ${ }^{1}$ and were originally intended to serve different niches within Canada's diverse health care system. ${ }^{3}$ However, this is currently not the case. Most centres do not differentiate between graduates of the two training streams. FRCPC-trained physicians often work in academic, tertiary care emergency departments, sharing the same case mix of patients and having equal responsibilities with non-FRCPCtrained physicians with varying levels of EM certification. At the same time, the majority of rural emergency departments are staffed by family practitioners with no formal EM certification. ${ }^{9}$
Numerous editorials have cited redundancies, inefficiencies, lost opportunity for synergy, and competition for resources as challenges faced by the dichotomous EM training process, questioning the need for two independent EM residency training programs. ${ }^{1-3,11}$ Although emergency physicians have been questioned regarding the need for and utility of these two separate EM training streams, to our knowledge, medical students have not been asked for their opinions regarding the issue. Therefore, the objective of this study was to assess medical students' knowledge of and attitudes toward the two Canadian EM residency training programs. Additionally, medical students interested in EM were asked to select factors affecting their preferred choice of residency training program and their intended future practice.

\section{METHODS}

Medical students enrolled at The University of Western Ontario for the 2008-2009 academic year were invited to complete a 47 -item questionnaire. An invitation to participate and a weblink to the online survey were sent to the medical students on four separate occasions between January and March 2009 using surveymonkey .com. Additionally, six of the authors were medical students and invited their peers to participate through a structured 2-minute verbal presentation outlining the objectives of the study and time commitment necessary for survey completion. This presentation was delivered once to the students in each year of medical study. Participation was completely voluntary and anonymous. Approval for this research study was obtained from the Health Sciences Research Ethics Board of The University of Western Ontario.

Medical students at The University of Western Ontario gain exposure to EM through a mandatory 2 -week rotation at an academic, tertiary care centre during their third year of medical school. This academic centre has both CCFP-EM and FRCPC residency training programs. Participants were asked 
demographic information and questions related to their knowledge, opinions, and attitudes toward EM residency training. Survey questions were created by the investigators based on a review of relevant literature and consultation with medical students, emergency physicians, and an epidemiologist. Specific factors affecting career choice were adopted from a previously published survey. ${ }^{12}$ Prior to distribution, the questionnaire was peer reviewed and tested for ease of language and comprehension. The full questionnaire can be viewed as Appendix I (available online).

\section{DATA ANALYSIS}

Descriptive statistics are reported as frequencies and percentages. Differences in proportions were assessed using the Pearson chi-square statistic. For the ranking of factors influencing program selection choice, a priority index score was calculated for each factor. Briefly, choices ranked first were assigned a score of 5 , choices ranked second were assigned a score of 4 , and so on. Total scores for each factor were derived by summing the assigned scores from each medical student. The total score for each factor determined its rank order from highest to lowest on the priority index. Data were analyzed using SPSS 16.0 (SPSS Inc, Chicago, IL).

\section{RESULTS}

Of the 563 students attending the Schulich School of Medicine and Dentistry at The University of Western Ontario, 406 (72.1\%) completed the survey and 50.4\% were male. The distribution of respondents across years of study was $26.9 \%$ in first year, $29.4 \%$ in second year, $18.2 \%$ in third year, and $25.5 \%$ in fourth year. Of the 406 survey respondents, 178 (43.8\%) expressed an interest in applying to an EM residency training program, with $85(47.8 \%)$ most interested in applying to the CCFP-EM program (Figure 1). Of the 178 students interested in EM, 127 (71.3\%) were in their preclinical years (years 1 and 2). Preclinical students were more interested in the FRCPC program compared to senior medical students $(81.8 \%$ v. $18.2 \%$; $p<0.01)$.

Table 1 lists the top five factors influencing decision making for respondents interested in EM. Although not ranked in the top five factors influencing decision making, perceived prestige/status was ranked significantly higher among respondents interested in FRCPC
(20.7\%) compared to respondents interested in CCFP$\operatorname{EM}(8.1 \%)(\Delta-12.6 \%$; $95 \%$ CI $-21.0 \%,-4.2 \%)$. The remaining factors were not rated differently between the two groups.

Figure 2 shows differences in medical students' perceptions regarding the degree of exposure each EM training stream provides. Most respondents interested in EM believed that the FRCPC program provided more exposure $(p<0.05)$ to $\mathrm{EM}(76.6 \%)$, research (59.4\%), and subspecialization (75.1\%) and that the CCFP-EM program offered more exposure $(p<0.05)$ to family medicine (78.3\%) and rural medicine $(56.6 \%)$.

Respondents were asked about their perceptions of the working environment following program completion (Figure 3). Students were asked to indicate if they believed graduates from the FRCPC or CCFPEM residency training programs were paid equally, worked the same number of hours per week, and experienced similar rates of "burnout." In general, respondents interested in CCFP-EM and FRCPC were in agreement, with no significant differences between the groups. Approximately one-third of these respondents perceived equal pay $(36.5 \%)$ and burnout rates $(36.5 \%)$ between the two streams, whereas $46 \%$ believed that graduates of the two residency programs worked equal hours per week. Interestingly, $34.3 \%$ believed that the FRCPC graduates were paid more, and $26.3 \%$ believed that FRCPC graduates experienced higher burnout rates.

Several questions were applicable only to respondents expressing interest in a specific stream. Respondents interested in FRCPC were asked if they intended to apply to a family medicine residency program as a "backup" plan in case they were not accepted into an FRCPC program. One participant chose not to answer this question. Of the remaining 54 respondents, 15 (27.8\%) would not apply to a family medicine program as a backup, $19(35.2 \%)$ would, and $20(37.0 \%)$ were unsure. Applicants interested in CCFP-EM were asked if they would disclose their intentions of pursuing a career in EM during the family medicine residency matching process. Of these 82 respondents, 40 (48.8\%) would disclose their EM intentions, 9 (11.0\%) would not, and 33 (40.2\%) were unsure.

Respondents interested in CCFP-EM were also asked how much time they wished to spend in family practice and EM after residency. The majority intended to practice mostly family medicine or half family medicine and half EM (Figure 4). 


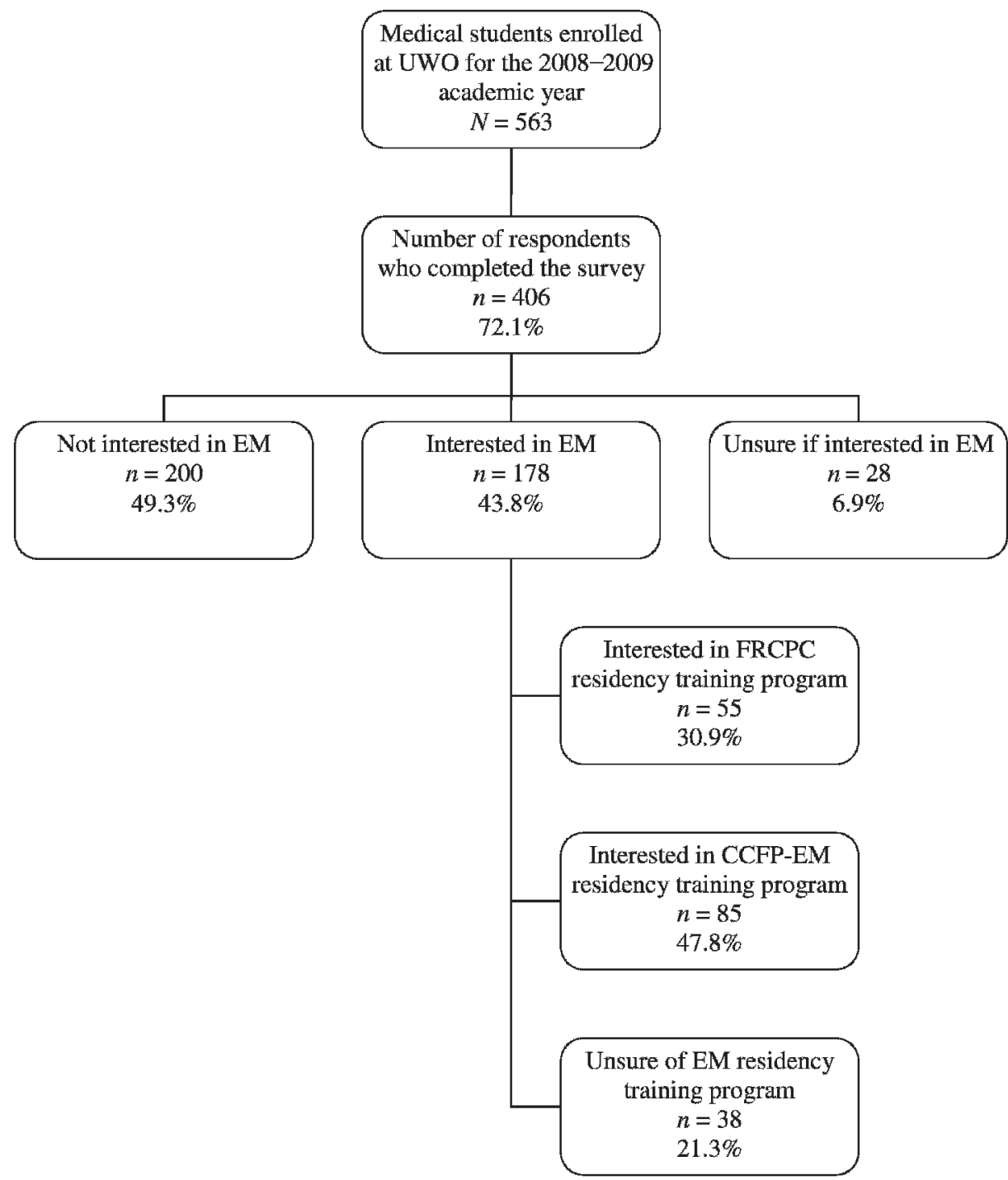

Figure 1. Flow diagram of respondents. CCFP-EM = Certificant of the College of Family Physicians-Emergency Medicine; $E M=$ emergency medicine; FRCPC $=$ Fellow of the Royal College of Physicians of Canada; UWO = University of Western Ontario.

The majority of respondents $(54.1 \%)$ believed that there should be two streams to EM certification, whereas $18.0 \%$ disagreed. The remainder were unsure. In terms of competency, 99 (57.6\%) respondents believed that FRCPC graduates are more competent on graduation, whereas 36 (20.9\%)

Table 1. Ranking of top five factors influencing decision making for respondents interested in emergency medicine

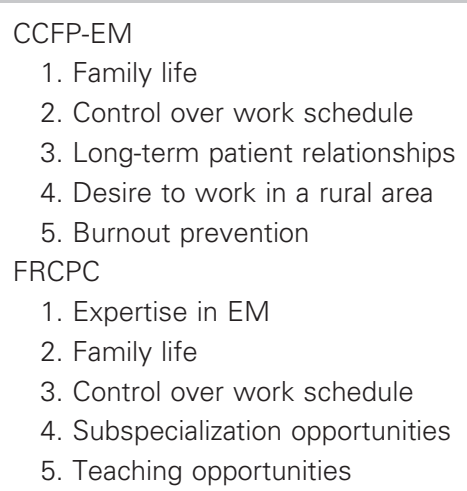

CCFP-EM = Canadian College of Family Physicians Emergency Medicine; EM = emergency medicine; FRCPC = Fellow of the Royal College of Physicians of Canada 


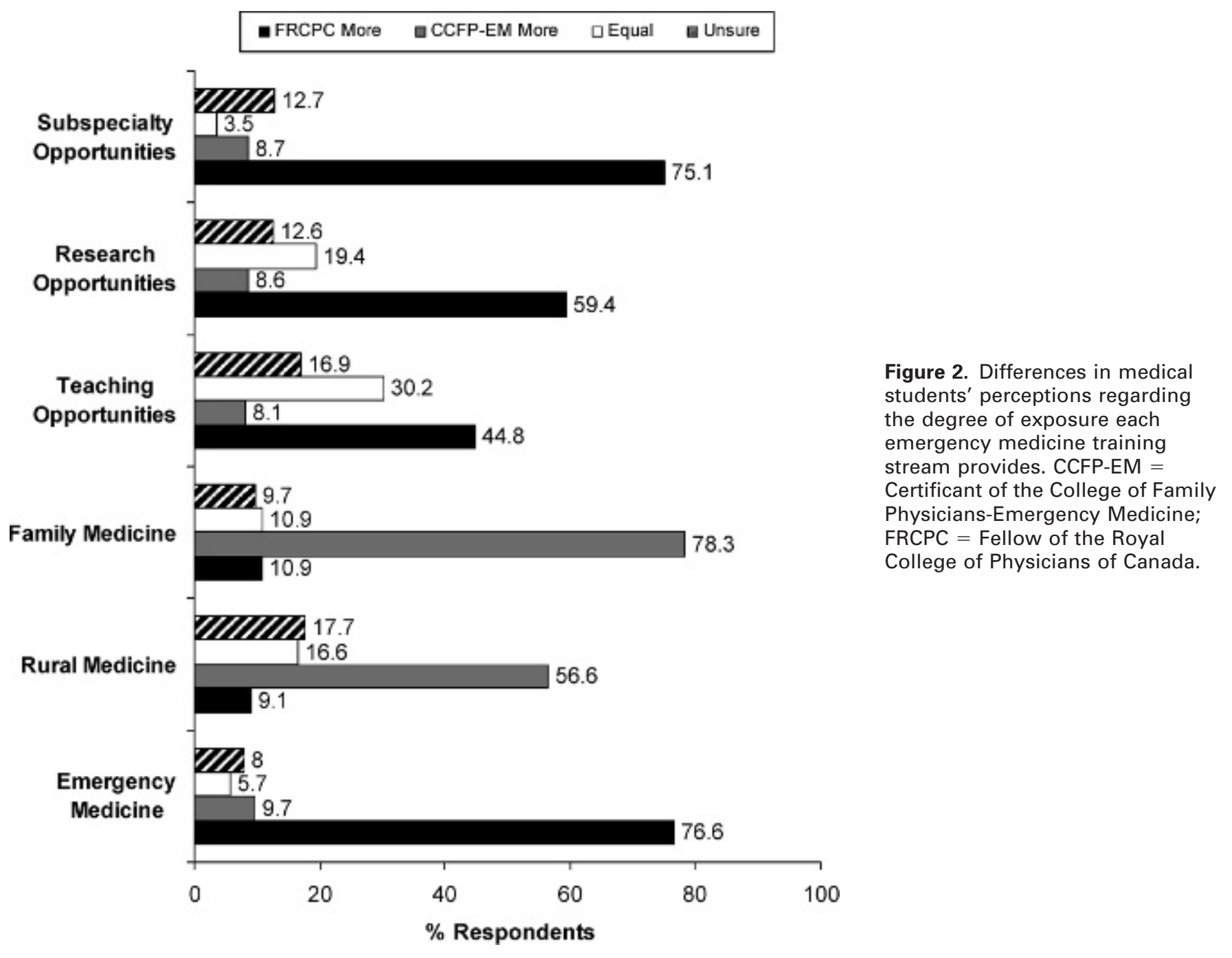

believed that graduates were equally competent. However, most respondents $(73.1 \%)$ believed that graduates from both streams are equally competent after 5 years of practice. When asked about the lengths of the two programs, $52(30.6 \%)$ respondents felt that the FRCPC program should not be shorter than 5 years, whereas $57(33.5 \%)$ believed that it should. In contrast, with respect to the length of the CCFP-EM program, 48 (58.5\%) respondents interested in CCFP-EM thought that the program should not be longer, whereas a similar number of respondents interested in FRCPC (59.3\%) thought that it should be longer than 2 years of family medicine training with 1 year of EM exposure. When asked about the treatment of residents and physicians by hospital staff, 75 (43.9\%) respondents thought that FRCPC residents are treated preferentially, whereas 21 $(12.3 \%)$ believed that both FRCPC and CCFP-EM residents are treated equally $(\Delta-31.6 \%$; 95\% CI $-22.2 \%,-39.9 \%)$. Although $55(32.0 \%)$ respondents thought that after residency training, staff consultants are treated equally, 48 (27.9\%) perceived that physician colleagues and other hospital staff treat FRCPC-trained physicians more favourably $(\Delta-4.1 \% ; 95 \%$ CI $-5.6 \%$, $1.4 \%)$. Interestingly, 41 (50.0\%) respondents interested in CCFP-EM and 24 (44.4\%) respondents interested in FRCPC felt that it was not acceptable to train in the CCFP-EM program and later practice full-time EM.

\section{DISCUSSION}

This is the first study describing differences in perceptions, preferences, and attitudes between medical students interested in the two Canadian EM residency training programs. 


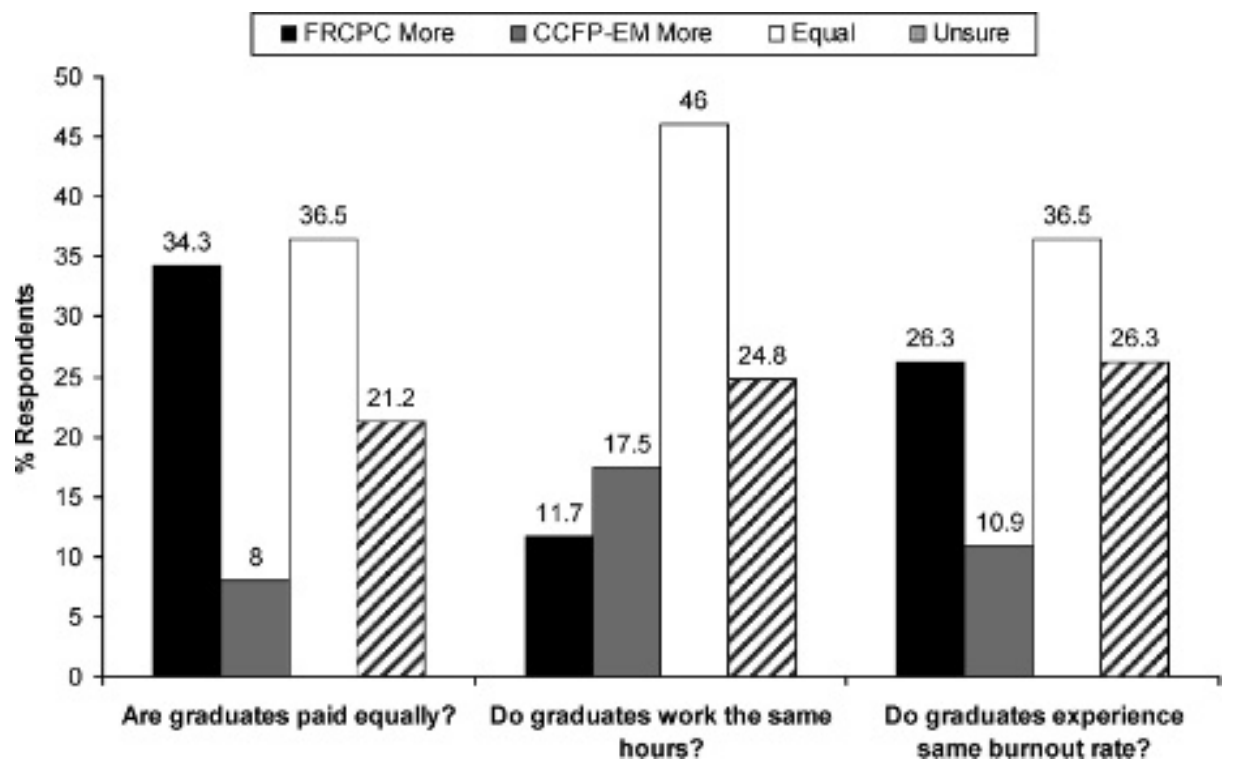

Figure 3. Differences in medical students' perceptions regarding the working environment following residency program completion. CCFP-EM = Certificant of the College of Family PhysiciansEmergency Medicine; FRCPC = Fellow of the Royal College of Physicians of Canada.

\section{Factors affecting decision making}

Many career factors and personal characteristics have been associated with a medical student choosing EM. These have included lifestyle factors such as flexibility in practice location and schedule, as well as clinical factors such as diversity of practice, interest in working in a hospital environment, and an emphasis on acute care. ${ }^{13,14}$ In agreement with previous studies, family life and control over work schedule were ranked among the top five factors by medical students interested in FRCPC and CCFP-EM programs and appear to be common priorities seen as benefits of any career in EM. However, the remaining factors were rated differently between the two interested groups. These findings highlight fundamental differences in the priorities of each group with respect to their anticipated practice environment in EM. An understanding of the differences between the two groups interested in EM may help educators and program directors in maximizing interest in their respective EM training programs.

\section{Perceptions of postgraduate work life}

The issue of "burnout" within EM has been discussed and strongly debated. ${ }^{15-18}$ Although there is mixed evidence and opinion regarding the degree of burnout experienced by emergency physicians compared to

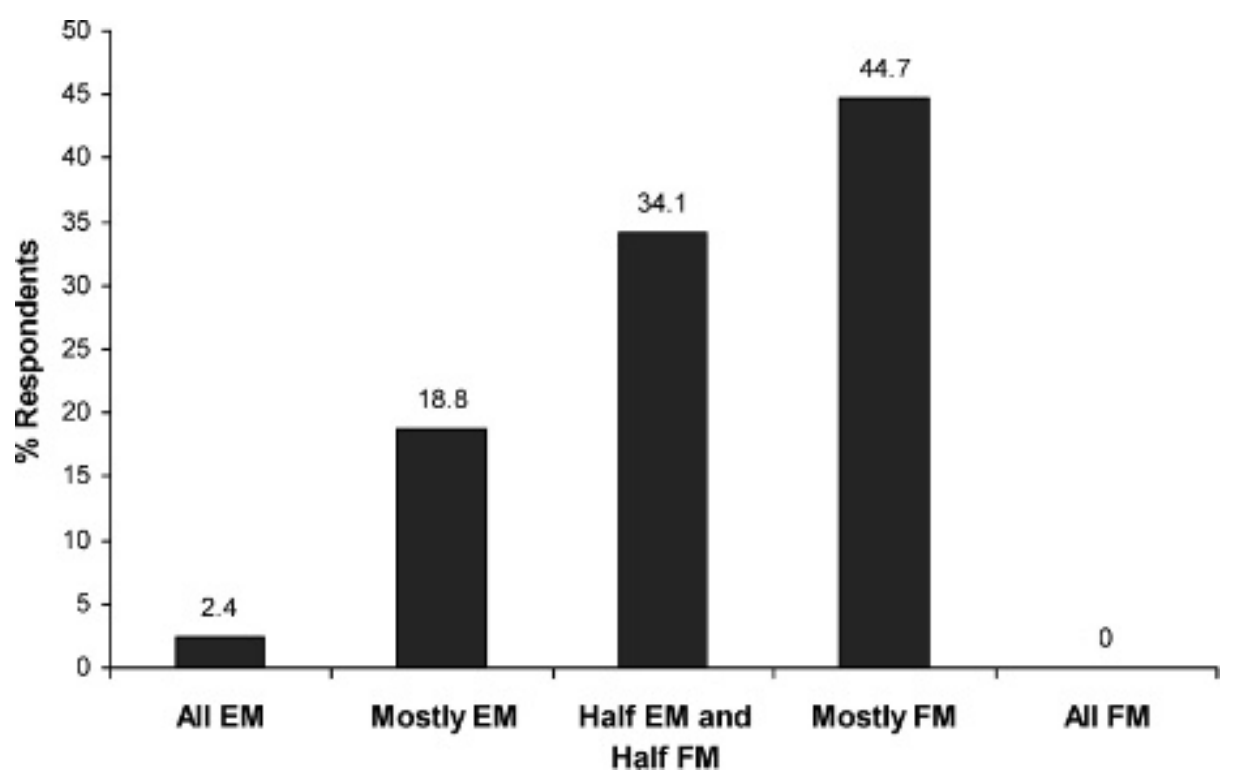

Figure 4. Proportion of time respondents interested in Certificant of the College of Family Physicians-Emergency Medicine (CCFP-EM) would like to spend practicing emergency medicine (EM) and family medicine (FM). 
other medical professionals, there seems to be a general consensus that EM is perceived as a career with high burnout potential. This study looked specifically at differences in perceived burnout between graduates of the two EM programs. Approximately one-quarter of respondents interested in practicing EM believed that FRCPC graduates will experience higher burnout rates than CCFP-EM graduates throughout their careers. The CCFP-EM interested group also ranked burnout prevention as one of the top five determinants of their choice of EM stream. It appears that many medical students feel that the CCFP-EM training program provides either an option for preventing burnout through a blended practice or a "fall-back" career if burnout in EM is experienced.

\section{"Backing up" in CCFP}

A recent editorial expressed concern about the educational "resource misallocation" that occurs when CCFPEM physicians spend 2 years training in family medicine and practice solely EM. ${ }^{3}$ In this survey, medical students who identified FRCPC as their preferred training route were asked if they intended to "back up" by applying to a family medicine/EM residency program with the sole purpose of increasing their chance to practice as an emergency physician. Almost one-third intended to "back up" in family medicine, with another one-third stating they were unsure. Of particular interest, a substantial proportion of medical students who identified an interest in one of the EM residency streams (46\%) believed that it is unacceptable for physicians to complete the CCFP-EM training program and practice full-time EM. These are important findings with respect to the residency matching process. EM is considered a competitive specialty in Canada, with consistently more FRCPC applicants than available training positions. Based on these results, there is the potential that students interested in the FRCPC training program are matching to family medicine programs with no intention of pursuing general practice. Ultimately, the CFPC, RCPSC, and EM community must determine if this is an acceptable use of limited residency training resources.

\section{Hours spent in EM versus family medicine}

We found that the majority of respondents who ranked CCFP-EM as their preferred method of EM certification intend to practice mostly family medicine or half family medicine and half EM. However, this finding is contradicted by Chan and Shepherd and Burden, who independently demonstrated that the majority of CCFP-EM-certified physicians practice "almost all" or "mostly" EM. ${ }^{8,19}$ It is possible that the current cohort of medical students has different priorities and interests than previous graduates of the CCFP-EM program and that they intend to better blend their EM and family practice. However, one cannot discount the possibility that the current cohort of students may change their minds during the training process and thus practice mostly or all EM. This explanation is supported by Shepherd and Burden, who showed that although $47 \%$ of respondents intended to engage in a blended practice on entrance to the 1-year CCFP-EM training program, less than $20 \%$ actually blended their practice after graduation.

\section{Attitudes regarding EM residency training}

Some emergency physicians have suggested an amalgamation of the two EM training programs and have proposed a 3- to 4-year EM residency with the option of postgraduate fellowship training to acquire subspecialty certification. ${ }^{2,3}$ However, the results from our study show that only $18 \%$ of respondents believed an amalgamation of the two EM training streams would be preferred.

The majority of respondents (54\%) felt that FRCPC graduates are more clinically competent on graduation compared to their CCFP-EM-trained colleagues. Interestingly, however, the vast majority (73\%) believed that graduates of both streams are equally competent after 5 years of practice. What is not clear is whether respondents believe that the quality of the FRCPC training program creates greater clinical competency or if this difference is simply due to the two additional years of residency training. The fact that the majority believe there is no difference in competency after 5 years of clinical practice seems to support the idea that medical students believe that more years of clinical experience result in greater competency rather than residency training alone.

It has been stated that CCFP-EM graduates feel like "second-class citizens" compared to their FRCPCtrained colleagues. ${ }^{10}$ Medical students surveyed in our study seemed to concur with this statement as only a small minority (12.3\%) believed that both FRCPC and CCFP-EM residents are treated equally by hospital 
staff. This perception of treatment inequality also applied to staff physicians as one-third of survey respondents believed that FRCPC graduates are treated preferentially. However, it is unknown whether this perceived disparity is due to differences in the quality of the residency curriculum, the quantity of clinical experience accrued, or dedication to EM as a full-time profession.

\section{LIMITATIONS}

This survey was distributed to only one medical school in Ontario and therefore cannot be generalized to all medical students across Canada. However, we had a relatively high response rate, with an equal representation of males and females across all 4 years of medical school. As with all voluntary questionnaires, selfselection bias may have existed. Additionally, the influence of social desirability bias in this study is unknown. To reduce the impact of such bias, participation in this study was completely voluntary and anonymous using a self-administered questionnaire. Although the questionnaire was internally validated and peer reviewed, there may be additional career factors that were not included. Furthermore, the actual career choice of this cohort of medical students has yet to be determined. It would be interesting to follow up with the same cohort of students on graduation and residency match.

This data set did not separate medical students into preclinical and clinical years of training. Future research should attempt to determine if and why differences in attitudes, perceptions, and preferences exist between years of medical training.

Although the perceptions of medical students (especially preclinical medical students) on the length of training and the competence of practice between the two EM programs are controversial and may not reflect the opinions of the EM community, the objective of this study was to assess medical students' knowledge of and attitudes toward the two Canadian EM residency training programs.

\section{CONCLUSIONS}

This is the first survey of Canadian medical students to describe differences in knowledge, preferences, and attitudes between those interested in the two Canadian EM residency training programs. Our findings suggest numerous disparities in factors influencing choice of residency stream, perceptions of postgraduate work life, and anticipated practice environment. An understanding of these differences may help leaders structure the future of EM residency training programs in Canada.

Competing interests: None declared.

\section{REFERENCES}

1. Ducharme J. Preparing emergency physicians for the future. CMA7 2003;168:1548-9.

2. Rutledge T. Emergency medicine training in Canada: learning from the past to prepare for the future. CFEM 2008;10:108-10.

3. Abu-Laban RB. Emergency medicine certification in Canada: the years march on but the questions remain the same. CFEM 2008;10:101-3.

4. Ovens H. EM training in Canada: two is better than one. CFEM 2008;10:319.

5. Drummond A. Is this really the right time for an identity crisis? C7EM 2008;10:320-1.

6. Langhan T. Emergency medicine certification in Canada. CFEM 2008;10:321-2.

7. Green R. EM dual training impacts the advancement of the specialty. CFEM 2008;10:322.

8. Chan BT. Do family physicians with emergency medicine certification actually practice family medicine? CMAJ 2002; 167:869-70.

9. Steiner IP. Emergency medicine practice and training in Canada. CMA7 2003;168:1549-50.

10. Campbell S. CCFP-EM versus FRCP [letter]. CfEM 2003; $5: 80$.

11. Moore K, Lucky C. Emergency medicine training in Canada. C7EM 1999;1:51-3.

12. Scott I, Gowans M, Wright B, et al. Why medical students switch careers. Can Fam Physician 2007;53:94-5.

13. Scott I, Abu-Laban R, Gowans M, et al. Emergency medicine as a career choice: a descriptive study of Canadian medical students. CFEM 2009;11:196-206.

14. Kazzi AA, Langdorf MI, Ghadishah D, et al. Motivations for a career in emergency medicine: a profile of the 1996 US applicant pool. CFEM 2001;3:99-104.

15. Chisholm C, Heyborne R, Short T, et al. Reflections about "burn-out." Acad Emerg Med 2009;16:567-71, doi:10.1111/ j.1553-2712.2009.00425.x.

16. Cydulka RK, Korte R. Career satisfaction in emergency medicine: the ABEM longitudinal study of emergency physicians. Ann Emerg Med 2008;51:714-22.e1. [Epub 2008 Apr 8], doi:10.1016/j.annemergmed.2008.01.005.

17. Gendreau M. Career satisfaction in emergency medicine and burnout: all is not well. Ann Emerg Med 2008;52:557, doi:10.1016/j.annemergmed.2008.06.470.

18. LeBlanc C, Heyworth J. Emergency physicians: "burned out" or "fired up"? CFEM 2007;9:121-3.

19. Shepherd LG, Burden JK. A survey of one CCFP-EM program's graduates: their background, intended type of practice and actual practice. CFEM 2005;7:315-20. 